\title{
n-Butane Isomerization over Silica-Supported Heteropolyacids: Study of Some Parameters
}

\author{
Eva Grinenval, Anthony Garron, and Frédéric Lefebvre \\ Université de Lyon, Institut de Chimie de Lyon, UMR C2P2, LCOMS, Bâtiment CPE Curien, \\ 43 Boulevard du 11 Novembre 1918, 69616 Villeurbanne, France \\ Correspondence should be addressed to Frédéric Lefebvre; lefebvre@cpe.fr
}

Received 24 January 2013; Accepted 22 April 2013

Academic Editor: Mohammed M. Bettahar

Copyright (C) 2013 Eva Grinenval et al. This is an open access article distributed under the Creative Commons Attribution License, which permits unrestricted use, distribution, and reproduction in any medium, provided the original work is properly cited.

Isomerization of $n$-butane was studied on silica-supported heteropolyacids. The activity depends strongly on the solvent used for the preparation and on the polyoxometalate loading. This behavior was explained by different proportions of isolated and bulk heteropolyacids. Silicotungstic acid is inherently more selective than phosphotungstic acid. In presence of platinum and hydrogen the catalysts are stable and highly selective (more than 97\%) to isobutane. A study as a function of temperature shows that there is an optimal temperature for performing the reaction.

\section{Introduction}

Skeletal isomerization of low carbon $n$-paraffins to isoparaffins is of great importance for the petroleum industry as it allows preparation of fuel mixtures of improved performance, low-octane-number compounds being replaced by highoctane-number ones [1]. As a consequence, the use of leadcontaining fuel additives could be suppressed completely, resulting in economic and environmental benefits. In particular, $n$-butane can be transformed to isobutane, which is used in the synthesis of MTBE (methyl-tert-butyl ether, another fuel additive) or in the alkylation of butenes [2].

Various alternatives have been tested so far in order to replace the currently employed commercial system $\mathrm{Pt} /$ $\mathrm{Cl}-\mathrm{Al}_{2} \mathrm{O}_{3}$ (which among other inconveniences is water sensitive and requires constant addition of a small quantity of organic chloride precursor to the feed gas) or Pt/mordenite (less active than the former but resistant to poisoning). Sulfated zirconia $\mathrm{SO}_{4}{ }^{2-} / \mathrm{ZrO}_{2}$ was, for instance, reported to catalyze butane-isobutane isomerization already at room temperature [3]. Although it deactivated rapidly, its activity was higher than those of zeolites and is rather similar to mordenite $[4,5]$. The presence of $\mathrm{H}_{2}$ in the feed gas was shown to increase and stabilize the activity even in the absence of a noble metal cocatalyst and was ascribed to the suppression of the agglomeration of polymeric cracking products at the surface of the catalyst. However, when the concentration of hydrogen was too high a inhibiting effect was noted [4]. Some other proposed systems for this reaction were based on sulfated titania $\mathrm{SO}_{4}{ }^{2-} / \mathrm{TiO}_{2}$ [6] or tungstated zirconia $\mathrm{WO}_{3} / \mathrm{ZrO}_{2}$ [7].

Polyoxometalates can be perceived as discreet analogues of metal oxide surfaces [8]. Particularly, the Keggin family members are widely used in homogenous catalysis, because of their pronounced and tuneable acidic and redox properties [9]. There are however only few examples of applications of pure solid heteropoly oxometalates in heterogeneous catalysis, due to their very low specific surface area (only few $\left.\mathrm{m}^{2} \cdot \mathrm{g}^{-1}\right)$. This problem can be solved easily by various ways such as the use of nonstoichiometric alkaline salts of polyoxometalates which have a high surface area (more than $100 \mathrm{~m}^{2} \cdot \mathrm{g}^{-1}$ ) [10]. Another possibility is to impregnate them on oxides such as silica. However, in this case they can be used only for gas-solid reactions or liquid-solid reactions with apolar reagents, due to their high solubility in polar compounds. As they are very acidic, they can be used in the isomerization and/or cracking reactions of alkanes such as $n$ hexane and $n$-heptane [11-26] but to our knowledge only the cesium salts were studied in the isomerization of $n$-butane to isobutene. This paper describes the use of silica-supported heteropolyacids for the isomerization of $n$-butane with the 
aim to study some parameters such as the solvent used for the impregnation, the polyoxometalate loading, or the reaction temperature.

\section{Experimental}

The tungsten-based heteropolyacids $\left(\mathrm{H}_{3} \mathrm{PW}_{12} \mathrm{O}_{40}\right.$ and $\mathrm{H}_{4} \mathrm{SiW}_{12} \mathrm{O}_{40}$ ) and the platinum source $\mathrm{H}_{2} \mathrm{PtCl}_{6}$ were purchased from Sigma-Aldrich and used as received.

The silica-supported catalysts were prepared as follows: a mixture of tungsten-based heteropolyacid dissolved in an organic or aqueous solution $(10 \mathrm{~mL}$ ) and silica (compacted and sieved flame silica Aerosil from Degussa, $200 \mathrm{~m}^{2} \cdot \mathrm{g}^{-1}$ ) was performed so as to obtain the desired loading on the oxide support. The suspension was stirred and evaporated to dryness at $80^{\circ} \mathrm{C}$.

The $\mathrm{Pt} / \mathrm{Al}_{2} \mathrm{O}_{3}$ catalyst was prepared by incipient wetness technique: $\gamma$-alumina (compacted and sieved $\gamma$-alumina from Degussa, $200 \mathrm{~m}^{2} \cdot \mathrm{g}^{-1}$ ) was impregnated with an aqueous solution of hexachloroplatinic acid ( $0.3 \mathrm{wt} \% \mathrm{of} \mathrm{Pt})$. The solid was subsequently calcinated in air at $550^{\circ} \mathrm{C}$ for $2 \mathrm{~h}$. The reduction under hydrogen takes place directly in the reactor at $225^{\circ} \mathrm{C}$ for $4 \mathrm{~h}$ with a flowing rate of $10 \mathrm{~mL} \cdot \mathrm{min}^{-1}$.

$n$-Butane isomerization reactions were performed in a flow reactor at atmospheric pressure or in a batch reactor with $n$-butane pressures of 2, 4, and 10 bars using $250 \mathrm{mg}$ of catalyst. For the contact time and activation energy studies, a mechanical mixture of 37.5 wt. $\% \mathrm{H}_{4} \mathrm{SiW}_{12} \mathrm{O}_{40} / \mathrm{SiO}_{2}$ prepared in water $(250 \mathrm{mg})$ with $0.3 \mathrm{wt} . \% \mathrm{Pt} / \mathrm{Al}_{2} \mathrm{O}_{3}(100 \mathrm{mg})$ was used. The catalyst placed into the continuous flow reactor was first reduced at $225^{\circ} \mathrm{C}$ for $4 \mathrm{~h}$ in hydrogen with a flowing rate of $10 \mathrm{~mL} \cdot \mathrm{min}^{-1}$. The contact time was varied between 0.143 and $0.571 \mathrm{~min}$ and the temperature between 100 and $350^{\circ} \mathrm{C}$. The other experiments were performed with a flowing rate of $1 \mathrm{~mL} \cdot \mathrm{min}^{-1}$ in $n$-butane without hydrogen at $225^{\circ} \mathrm{C}$.

\section{Results and Discussion}

3.1. General Considerations on Silica-Supported Heteropolyacids Alone. The silica-supported heteropolyacids are active in the isomerization of butane to isobutane at $225^{\circ} \mathrm{C}$ (Figure 1), in agreement with what is known in the literature with other POM-based systems and/or other alkanes (typically $n$-hexane and $n$-heptane) $[19,26]$. The selectivity is high (more than $90 \%$, whatever the polyoxometalate loading and the solvent used for the impregnation), with the other products being mainly $\mathrm{C}_{3}$ and $\mathrm{C}_{5}$ hydrocarbons (see Table 1 ), and remains quite constant along the entire test (see Figures 3 and 4).

As it can be seen on Figure 1, the activity decreases with time on stream. This deactivation is always observed on acid catalysts [23] and is related to the mechanisms of the isomerization reaction (see Schemes 2 and 3) and to the formation of coke. This decrease does not allow an easy comparison of different systems as various parameters should be taken into account such as the initial activity, the steady-state activity, and the deactivation rate. We decided then to model the deactivation curves in order to obtain

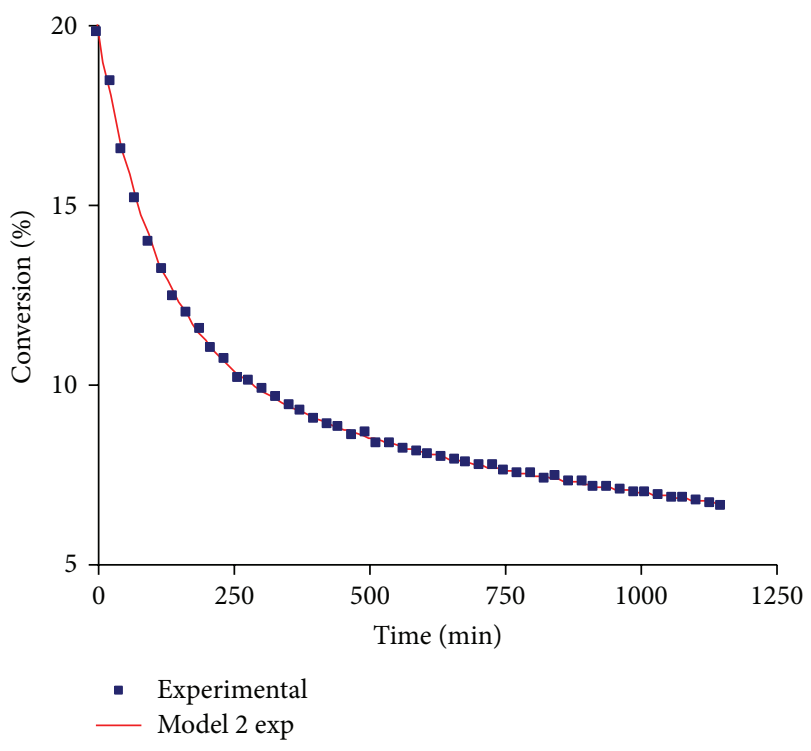

(a)

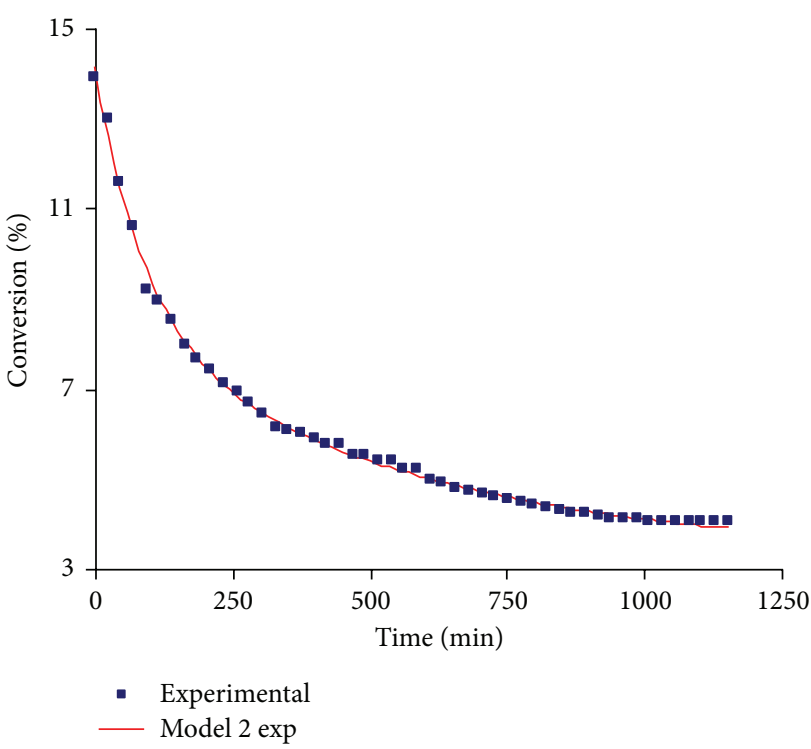

(b)

FIgURE 1: $n$-butane isomerization on $37.5 \mathrm{wt} . \% \mathrm{H}_{4} \mathrm{SiW}_{12} \mathrm{O}_{40} / \mathrm{SiO}_{2}$ (a) and 37.5 wt. $\% \mathrm{H}_{3} \mathrm{PW}_{12} \mathrm{O}_{40} / \mathrm{SiO}_{2}$ (b). Experimental points and best modeled curves.

parameters which could allow obtaining these values. For that purpose we tested different equations with the aim of (i) having the best fit of the conversion $=f$ (time) curves and (ii) using the same equation for all experiments made in the same conditions (only $n$-butane in the feed and $T=$ $225^{\circ} \mathrm{C}$ ). The sum of one constant term and of two exponential functions allowed such a good fit as shown in Figure 1:

$$
\operatorname{conv}=\operatorname{conv}(t=\infty)+A_{1} \cdot \exp \left(-\frac{t}{T_{1}}\right)+A_{2} \cdot \exp \left(-\frac{t}{T_{2}}\right)
$$


TABLE 1: Selectivity values of the different $\mathrm{H}_{3} \mathrm{PW}_{12} \mathrm{O}_{40} / \mathrm{SiO}_{2}$ catalysts at $t=1000 \mathrm{~min}$.

\begin{tabular}{|c|c|c|c|c|c|c|c|c|}
\hline \multirow{2}{*}{$\begin{array}{l}\text { HPW loading } \\
\text { (wt.\%) }\end{array}$} & \multirow{2}{*}{ Impregnation solvent } & \multicolumn{7}{|c|}{ Selectivities (\%) } \\
\hline & & $\mathrm{C}_{1}$ & $\mathrm{C}_{2}$ & $\mathrm{C}_{3}$ & $i-\mathrm{C}_{4}$ & $\mathrm{C}_{5}$ & $\mathrm{C}_{3}=$ & $\mathrm{C}_{4}=$ \\
\hline 37.5 & Acetonitrile & 0.0 & 0.1 & 2.8 & 92.4 & 4.5 & 0.0 & 0.0 \\
\hline 37.5 & Acetone & 0.0 & 0.1 & 1.9 & 94.0 & 3.3 & 0.0 & 0.7 \\
\hline 37.5 & Water & 0.0 & 0.1 & 2.1 & 93.3 & 3.7 & 0.0 & 0.8 \\
\hline 37.5 & THF & 0.0 & 0.1 & 1.6 & 94.4 & 2.8 & 0.0 & 1.1 \\
\hline 37.5 & Methanol & 0.0 & 0.1 & 2.4 & 92.6 & 4.2 & 0.0 & 0.7 \\
\hline $5.0^{*}$ & Water & 0.1 & 0.1 & 2.4 & 77.1 & 10.0 & 0.1 & 10.2 \\
\hline 20.0 & Water & 0.0 & 0.0 & 1.7 & 94.9 & 3.1 & 0.0 & 0.2 \\
\hline 37.5 & Water & 0.0 & 0.1 & 2.1 & 93.3 & 3.7 & 0.0 & 0.8 \\
\hline 50.0 & Water & 0.0 & 0.1 & 2.1 & 93.7 & 3.9 & 0.1 & 0.1 \\
\hline 75.0 & Water & 0.0 & 0.1 & 3.0 & 91.7 & 5.0 & 0.0 & 0.1 \\
\hline
\end{tabular}

${ }^{*}$ Values to be taken with care due to the very low conversion.

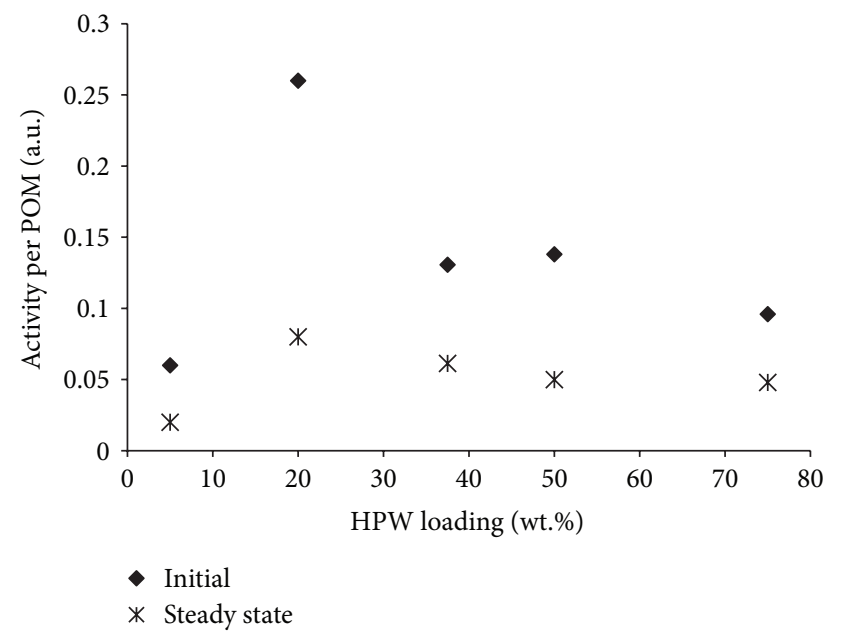

FIgURE 2: Evolution of the initial and steady-state activities per polyoxometalate as a function of the loading.

All curves were therefore fitted with 5 parameters. As this equation is only based on empirical considerations, some of these values are not significant from a physical point of view and the following numbers were deduced from them:

(i) the initial conversion $\operatorname{conv}(t=\infty)+A_{1}+A_{2}$,

(ii) the steady-state conversion $\operatorname{conv}(t=\infty)$,

(iii) the deactivation rate, expressed as the time corresponding to half of the conversion decrease $[\operatorname{conv}(t=$ $0)+\operatorname{conv}(t=\infty)] / 2$.

These values are given in Table 2 for all catalysts and allow to have a direct representation of the effect on the activity of the parameters which were studied: (i) effect of the solvent used for the impregnation at a given loading (37.5 wt.\%), (ii) effect of the loading for a given solvent (acetonitrile), and (iii) effect of the polyoxometalate $\left(\mathrm{H}_{3} \mathrm{PW}_{12} \mathrm{O}_{40}\right.$ versus $\mathrm{H}_{4} \mathrm{SiW}_{12} \mathrm{O}_{40}$ ) for the same loading (37.5 wt.\%) and the same solvent (water).

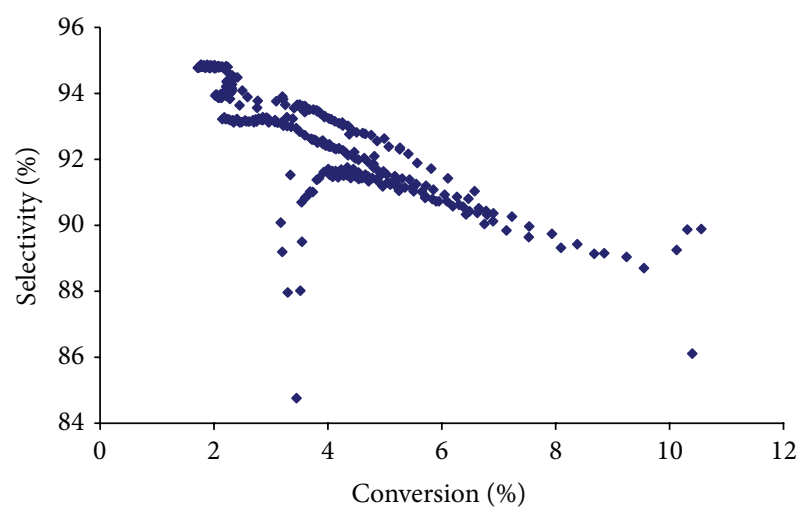

FIgURE 3: Selectivity to isobutane as a function of the conversion for all experiments with $\mathrm{H}_{3} \mathrm{PW}_{12} \mathrm{O}_{40} / \mathrm{SiO}_{2}$.

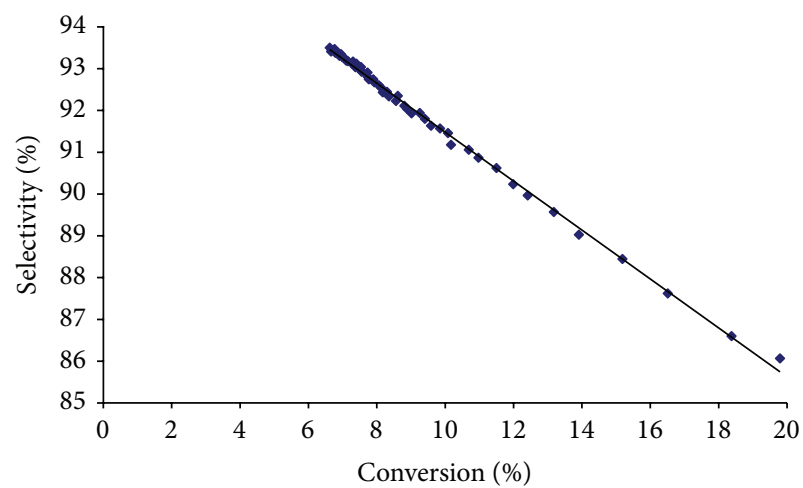

FIGURE 4: Selectivity to isobutane as a function of the conversion for all experiments with $\mathrm{H}_{4} \mathrm{SiW}_{12} \mathrm{O}_{40} / \mathrm{SiO}_{2}$.

3.2. Effect of the Impregnation Solvent. When looking at the data of Table 2 it is obvious that the solvent used for the preparation of the catalyst has a great influence on the initial conversion. The best solvents are methanol and water, while THF is the worst one, with acetone and acetonitrile giving intermediate values. The data obtained for two different 
TABLE 2: Initial and steady-state conversion and deactivation rate for the different silica-supported polyoxometalates.

\begin{tabular}{|c|c|c|c|c|c|}
\hline Polyacid & Solvent & $\begin{array}{c}\text { Loading } \\
\text { (wt.\%) }\end{array}$ & $\begin{array}{c}\text { Initial } \\
\text { conversion } \\
(\%)\end{array}$ & $\begin{array}{c}\text { Steady-state } \\
\text { conversion } \\
(\%)\end{array}$ & $\begin{array}{c}\text { Deactivation } \\
\text { rate (min) }\end{array}$ \\
\hline \multirow{6}{*}{$\mathrm{H}_{3} \mathrm{PW}_{12} \mathrm{O}_{40}$} & Methanol & \multirow{6}{*}{37.5} & 11.5 & 3.4 & 145 \\
\hline & Water* & & 10.9 & 2.6 & 165 \\
\hline & & & 14.2 & 3.3 & 130 \\
\hline & Acetonitrile & & 4.9 & 2.3 & 195 \\
\hline & Acetone & & 3.1 & 2.2 & 25 \\
\hline & THF & & 0.5 & 1.2 & - \\
\hline \multirow{5}{*}{$\mathrm{H}_{3} \mathrm{PW}_{12} \mathrm{O}_{40}$} & \multirow{5}{*}{ Acetonitrile } & 5 & 0.3 & 0.1 & 65 \\
\hline & & 20 & 5.2 & 1.6 & 35 \\
\hline & & 37.5 & 4.9 & 2.3 & 195 \\
\hline & & 50 & 6.9 & 2.5 & 250 \\
\hline & & 75 & 7.2 & 3.6 & 330 \\
\hline \multirow{2}{*}{$\mathrm{H}_{3} \mathrm{PW}_{12} \mathrm{O}_{40}$} & \multirow{3}{*}{ Water } & \multirow{3}{*}{37.5} & 10.9 & 2.6 & 165 \\
\hline & & & 14.2 & 3.3 & 130 \\
\hline $\mathrm{H}_{4} \mathrm{SiW}_{12} \mathrm{O}_{40}$ & & & 20.0 & 5.1 & 140 \\
\hline
\end{tabular}

${ }^{*}$ Two different preparations of the catalyst.

preparations of the same catalyst in water give an idea of the reproducibility of the experiments and of the precision of data of Table 2. These results are in agreement with the literature as the impregnation of heteropolyacids is often made in water or in methanol, even if some groups have reported the use of other organic solvents. However our data show that the solvent has no influence (or only a small influence) on the steady-state conversion, with quite the same value being obtained in all cases (with the exception of THF which shows a completely different behavior). Acetonitrile, water, and methanol give also quite the same deactivation rate, while the deactivation is more rapid with acetone. These differences from one solvent to another are probably related to the structure of the supported heteropolyacid. Indeed it is well known that various forms of supported polyoxometalates exist at the silica surface, as depicted in Scheme 1 [25].

Typically the polyacid can be isolated on the silica surface and interact with it by protonation of hydroxyl groups [27], or as crystallites of bulk $\mathrm{H}_{3} \mathrm{PW}_{12} \mathrm{O}_{40}$. As $n$-butane is apolar, the molecules cannot go inside the crystallites and so the reaction will occur only at the surface of the crystallites and with the protons of the isolated polyacids. The role of the solvent is then to increase the amount of isolated species compared to the bulk ones, or in other words to increase the dispersion of the polyoxometalate on the silica support. Such an effect had been reported for $\mathrm{H}_{4} \mathrm{SiW}_{12} \mathrm{O}_{40}$ on various substrates [28]. From a thermodynamic point of view the crystallites are formed by polyoxometalates, solvent molecules, and protons coordinated to solvent. If these crystals are more stable than the isolated polyoxometalate interacting with hydroxyl groups, the surface will mainly be covered by them. If there is no difference, or only a small difference, as in the case of water, the amount of isolated species will be higher. So, according to the initial conversion, the crystallization of
$\mathrm{H}_{3} \mathrm{PW}_{12} \mathrm{O}_{40}$ in THF gives species more stable than those obtained with acetone or acetonitrile which are more stable than those obtained with water or methanol.

3.3. Effect of the Polyoxometalate Loading. This study was made with impregnation in acetonitrile. Indeed this effect is well documented in the case of impregnation in water or methanol (see, e.g., [29]) but nothing has been reported in the case of acetonitrile. Our data show a continuous increase of not only the initial and steady-state conversions but also of the deactivation rate with the polyoxometalate loading. As all experiments were performed with the same amount of catalyst, the quantity of heteropolyacid (which is the active species, with silica being inactive in the activation of alkanes) was not the same in all cases. However, if we assume that the reaction takes place in chemical regime, the rate is proportional to the amount of catalyst and so the ratio of the conversion to the polyoxometalate loading will be representative of the intrinsic activity of the polyoxometalate for a given catalyst. Figure 2 shows the variation of this ratio (for the initial and steady-state conversions) as a function of the polyoxometalate loading.

This curve is quite similar to the one obtained in the case of $n$-hexane cracking [26]. The activity (initial or steady state) is very low for low loadings, and then it increases, reaches a maximum for ca. $20 \mathrm{wt} . \%$, and finally slightly decreases. These data can be explained by using the same distribution scheme on the surface as previously explained. For high loadings the polyoxometalate is mainly in the form of crystallites while for low loadings it is mainly in the form of isolated species. These isolated species can interact with the surface via one, two, or three silanol groups, with the preferential coordination mode being by three silanol groups [30]. As a consequence of low loadings there are no available protons 


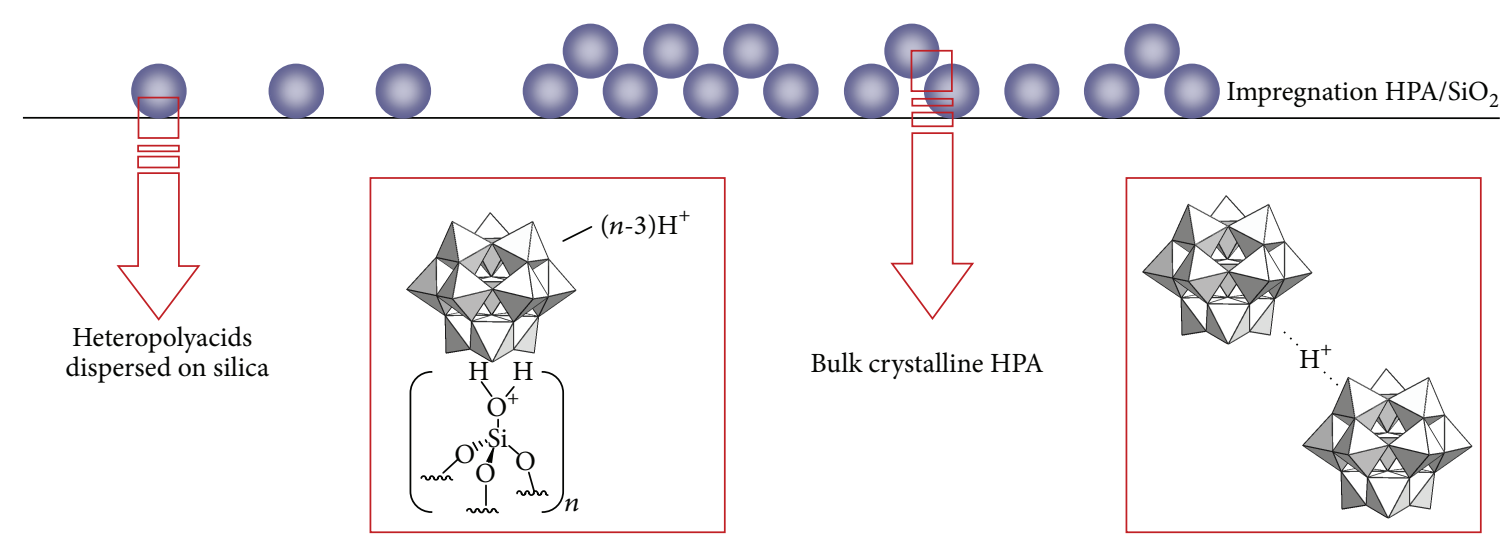

Scheme 1: Type of heteropolyacids on the silica surface.

and the catalyst is inactive. When the loading increases, new species appear on the surface: isolated polyoxometalates linked to silica by one or two bonds (and thus keeping some acidity) and microcrystals of bulk polyoxometalate. The latter ones become predominant at very high loadings, and the size of the microcrystals increases with the loading.

3.4. Effect of the Polyoxometalate. As $\mathrm{H}_{4} \mathrm{SiW}_{12} \mathrm{O}_{40}$ has more protons than $\mathrm{H}_{3} \mathrm{PW}_{12} \mathrm{O}_{40}$, and the silicotungstic acid is more active. Indeed, even if three protons are engaged in the coordination with silica, one of them will remain intact with this compound. Indirect proofs of this behavior were observed when reacting silica-supported heteropolyacids with organometallic complexes [31, 32]; quite no reaction occurred for $\mathrm{H}_{3} \mathrm{PW}_{12} \mathrm{O}_{40} / \mathrm{SiO}_{2}$ while a stoichiometric one was observed for $\mathrm{H}_{4} \mathrm{SiW}_{12} \mathrm{O}_{40} / \mathrm{SiO}_{2}$. The small decrease of acidity strength from phosphotungstic to silicotungstic acids does not result in a strong decrease of the catalytic activity per acidic proton sufficient to compensate the higher number of sites.

3.5. Selectivity to Isobutane. Figure 3 shows the variation of the selectivity to isobutene as a function of the conversion for all the above experiments with $\mathrm{H}_{3} \mathrm{PW}_{12} \mathrm{O}_{40}$. It is worth noting that all data as a function of time are taken into account (more than 300 points). If one excepts few points all data are on the same curve. Figure 4 shows the same data for $\mathrm{H}_{4} \mathrm{SiW}_{12} \mathrm{O}_{40} / \mathrm{SiO}_{2}$.

When looking at these curves the following conclusions can be made: (i) in all cases the selectivity decreases slightly when the conversion increases; (ii) for the $\mathrm{H}_{3} \mathrm{PW}_{12} \mathrm{O}_{40} / \mathrm{SiO}_{2}$ the selectivity does not depend on the polyoxometalate loading or on the solvent used for the preparation; (iii) $\mathrm{H}_{4} \mathrm{SiW}_{12}$ $\mathrm{O}_{40} / \mathrm{SiO}_{2}$ is intrinsically more selective than $\mathrm{H}_{3} \mathrm{PW}_{12} \mathrm{O}_{40} /$ $\mathrm{SiO}_{2}$ because whatever the conversion the selectivity to isobutane is always higher with the silicotungstic acid. Fitting the data with linear tendency curves gives

$$
\begin{aligned}
& \text { Selectivity }=97.3-0.58 * \text { conv for } \mathrm{H}_{4} \mathrm{SiW}_{12} \mathrm{O}_{40} \\
& \text { Selectivity }=95.5-0.77 * \text { conv for } \mathrm{H}_{3} \mathrm{PW}_{12} \mathrm{O}_{40} .
\end{aligned}
$$

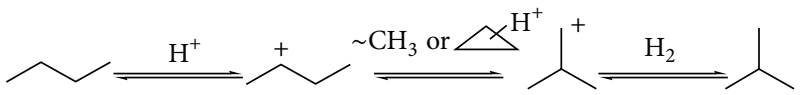

SCHEME 2: Monomolecular pathway of $n$-butane isomerization.

$$
n \mathrm{C}_{4} \underset{\text { Dehydrogenation }}{\stackrel{-\mathrm{H}_{2}}{\rightleftharpoons}} n \mathrm{C}_{4}=\underset{\begin{array}{c}
\text { Isomerization } \\
\text { Dimerization }
\end{array}}{\rightleftharpoons} i \mathrm{C}_{4}=\frac{\mathrm{H}_{2}}{\mathrm{C}_{8}} i \mathrm{C}_{4}
$$

SCHEME 3: Bimolecular pathway of $n$-butane isomerization.

So the selectivity at zero conversion is higher, but cannot achieve, in theseconditions, $100 \%$. Another point is that the slope of the curve is smaller for the silicotungstic acid and so at high conversion the difference between the two polyoxometalates will be higher. To our knowledge these points have never been reported in the literature and they prove definitively that $\mathrm{H}_{4} \mathrm{SiW}_{12} \mathrm{O}_{40}$ is a better candidate than $\mathrm{H}_{3} \mathrm{PW}_{12} \mathrm{O}_{40}$ for the $n$-butane isomerization.

3.6. Study of Bifunctional Systems. The stability of acid catalysts can be enhanced by using bifunctional systems corresponding to the introduction of a platinum source. Thus mechanistic studies have shown that the isomerization of alkanes can follow a mono- or a bimolecular pathway (see Schemes 2 and 3) $[33,34]$ depending on the strength of acid catalysts and the reaction temperature.

The monomolecular pathway starts with a hydride abstraction accompanied by hydrogen release and creation of a secondary $\mathrm{C}_{4}$ carbocation. Then intermediates formed either by a methyl transfer or a protonated cyclopropane lead to a very unstable primary carbocation. Finally a hydride transfer from hydrogen releases isobutane and regenerates the acid function of catalyst. If isomerization could proceed exclusively via this way, the selectivity to isobutane could reach $100 \%$. However the efficiency of the monomolecular 
process is limited by thermodynamics. In the equilibrium conditions, the conversion to isobutane can only reach $65 \%$ at $500 \mathrm{~K}$ [35]. In the monomolecular case, the catalyst displays a strong enough acidity to perform the isomerization at low temperature, and the platinum enhances the system stability by decreasing the formation of carbonaceous deposits on the catalyst surface that causes its deactivation. Unfortunately some cations can lead to butenes. In an acidic environment, the resulting olefins can be protonated and yield additional carbocations, but they are also able to couple with already existing ones. As a result, various $\mathrm{C}_{8}$ intermediate species are created and their concomitant rearrangements and scissions lead to the presence of a wide range of low carbon compounds (mainly $\mathrm{C}_{3}-\mathrm{C}_{5}$ but $\mathrm{C}_{1}$ and $\mathrm{C}_{2}$ can also be observed by hydrogenolysis over Pt sites). Even if the formation of isobutane via this route is possible, its selectivity decreases strongly. Moreover, as for the monomolecular pathway, the formation of carbonaceous deposits on the catalyst surface is responsible for its deactivation. The contribution of both routes is strongly temperature dependent as it has been evidenced by mechanistic studies using ${ }^{13} \mathrm{C}$-labeled $n$-butane $[15,16]$. At ca. $100^{\circ} \mathrm{C}$ the monomolecular route prevails but when the temperature rises to $200^{\circ} \mathrm{C}$ the bimolecular mechanism becomes predominant.

To complete our study, platinum was introduced in the catalytic system and hydrogen was added in the feed. Two preparation methods were used: the impregnation of a platinum salt on the silica-supported heteropolyacid and the mechanical mixing of supported heteropolyacid and a classical Pt $/ \mathrm{Al}_{2} \mathrm{O}_{3}$ catalyst. The main interest of the second method is the fact that the dispersion of platinum can be well controlled while in the first case it is more difficult and the reduction step can influence the performance of the catalyst by reducing also the polyoxometalate. The results are shown in Figure 5. Clearly the catalyst prepared by impregnation of $\mathrm{H}_{2} \mathrm{PtCl}_{6}$ on the supported polyoxometalate is more efficient even if it deactivates slightly (the rate is ca. $30 \%$ higher than the conversion achieved by mechanical mixing). This is probably related to a lower distance between the two sites, acidic proton and metal particle. However the fact that a mechanical mixing gives a stable system strongly favours the effect of platinum in the hydrogenation of olefins, preventing therefore the bimolecular pathway.

Another interesting feature is the comparison of the $\mathrm{H}_{4} \mathrm{SiW}_{12} \mathrm{O}_{40}$ - and $\mathrm{H}_{3} \mathrm{PW}_{12} \mathrm{O}_{40}$-based systems. Here also the silicotungstic acid leads to more selective systems (Table 3 ) and to a higher activity. Note that the selectivity values of all these systems are always higher than those achieved without platinum, whatever the activity, in agreement with a reaction occurring mainly via the monomolecular pathway.

Finally, we studied the effect of the temperature on the reaction rate. The system chosen for this study was $\mathrm{H}_{4} \mathrm{SiW}_{12}$ $\mathrm{O}_{40} / \mathrm{SiO}_{2}+\mathrm{Pt} / \mathrm{Al}_{2} \mathrm{O}_{3}$ but the conclusions will also be valid for the other catalysts. The results are displayed on Figure 6.

Clearly at high temperature (above $300^{\circ} \mathrm{C}$ ) the catalyst does not fit an Arrhenius plot, with the conversion remaining quite constant. This behavior is probably related to the loss of protons of the heteropolyacid at high temperature, by

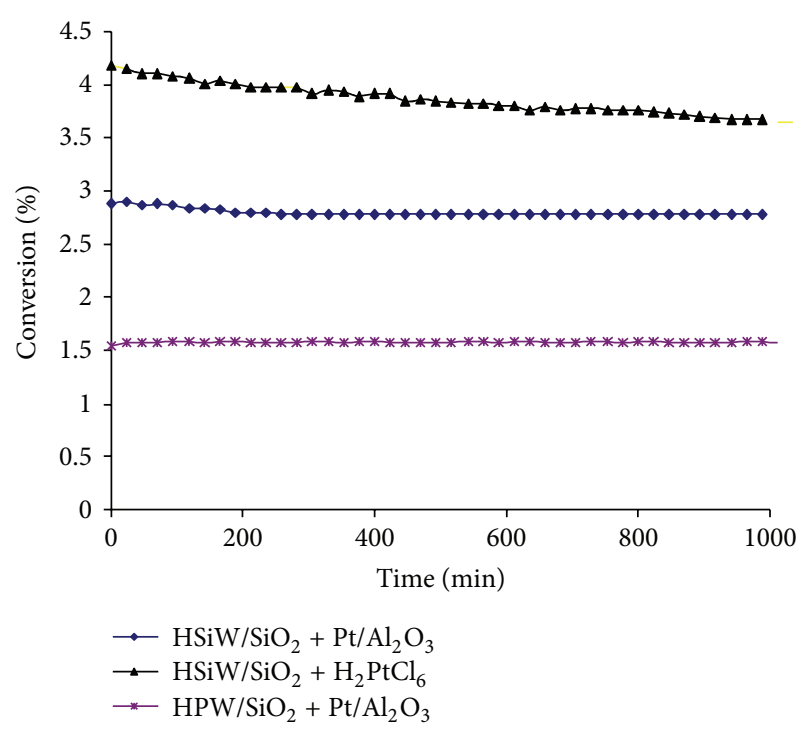

FIGURE 5: Conversion as a function of time for the bifunctional catalysts.

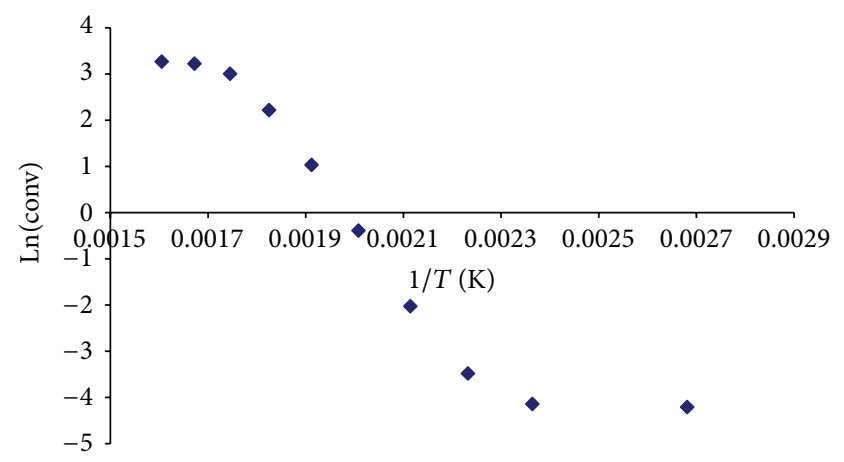

Figure 6: Arrhenius plot for the $37.5 \mathrm{wt} . \% \mathrm{H}_{4} \mathrm{SiW}_{12} \mathrm{O}_{40} / \mathrm{SiO}_{2}$ $(25 \mathrm{mg})+0.3 \mathrm{wt} . \% \mathrm{Pt} / \mathrm{Al}_{2} \mathrm{O}_{3} \quad(100 \mathrm{mg})$ catalyst (hydrogen $2.5 \mathrm{~mL} \cdot \mathrm{min}^{-1}$, butane $\left.1.0 \mathrm{~mL} \cdot \mathrm{min}^{-1}\right)$.

condensation and evolution of water molecules. In the bulk this reaction occurs at higher temperatures (above 400$450^{\circ} \mathrm{C}$ ) but very probably the protons located on the surface are lost at a more moderate temperature, possibly by a reaction with the silica hydroxyl groups.

At lower temperatures the curve fits well an Arrhenius plot. The activation energy deduced from these measurements $\left(112 \mathrm{~kJ} \cdot \mathrm{mol}^{-1}\right)$ is in good agreement with the literature data: the activation energy is $105-135 \mathrm{~kJ} \cdot \mathrm{mol}^{-1}$ on $\mathrm{Pt} / \mathrm{Cs}_{x}$ $\mathrm{H}_{3-x} \mathrm{PW}_{12} \mathrm{O}_{40}$ [36] or $90-110 \mathrm{~kJ} \cdot \mathrm{mol}^{-1}$ for more general acid mechanism [33].

3.7. Effect of Butane Pressure. From an industrial point of view working at pressures higher than atmospheric pressure is often very interesting as it allows the use of smaller installations while the conversion is increased. We have then studied the effect of the butane pressure on the catalytic activity of the $\mathrm{H}_{4} \mathrm{SiW}_{12} \mathrm{O}_{40} / \mathrm{SiO}_{2}$ catalyst (at the same loading than above). As these experiments were not made on the same reactor as above with slightly different experimental 
TABLE 3: Selectivity values of bifunctional catalysts.

\begin{tabular}{lcccccc}
\hline Catalyst & \multicolumn{3}{c}{ Selectivities (\%) } & $\mathrm{C}_{5}$ & $\mathrm{C}_{3}=\mathrm{C}_{4}=$ \\
\hline $\mathrm{HSiW} / \mathrm{SiO}_{2}+\mathrm{H}_{2} \mathrm{PtCl}_{6}$ & 0.1 & 0.3 & 1.0 & 97.5 & 1.0 & 0.0 \\
$\mathrm{HSiW} / \mathrm{CiO}_{2}+\mathrm{Pt} / \mathrm{Al}_{2} \mathrm{O}_{3}$ & 0.1 & 0.6 & 0.7 & 97.9 & 0.6 & 0.0 \\
$\mathrm{HPW} / \mathrm{SiO}_{2}+\mathrm{Pt} / \mathrm{Al}_{2} \mathrm{O}_{3}$ & 0.7 & 2.0 & 2.3 & 94.2 & 0.9 & 0.0 \\
\hline
\end{tabular}

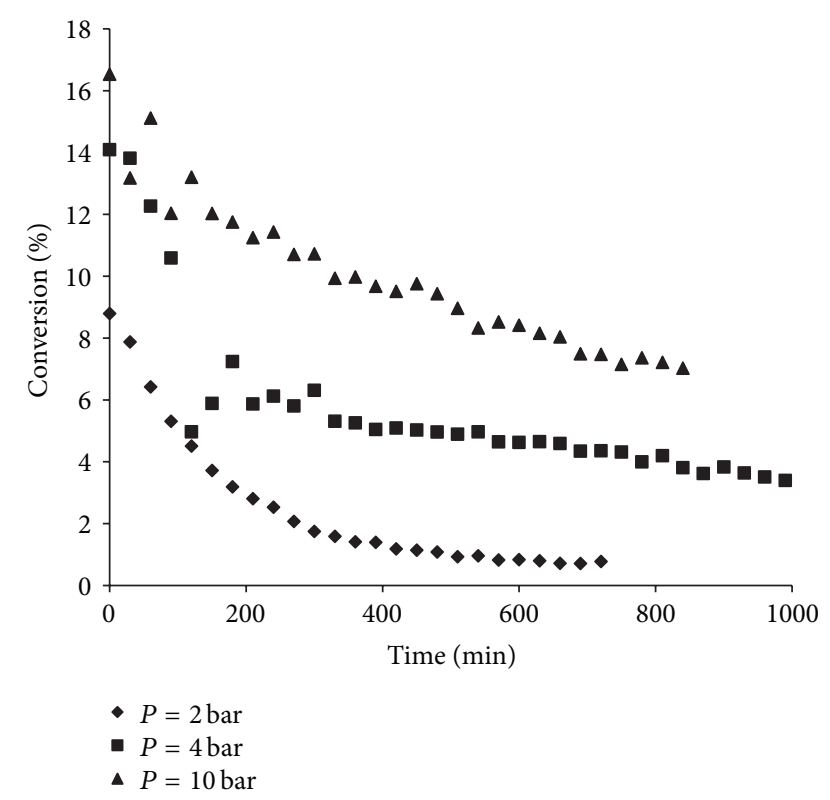

FIGURE 7: Effect of butane pressure on the conversion as a function of time.

conditions (the amount of catalyst was lower) these data cannot be compared directly to those described above but tendencies can be drawn. Figure 7 shows the conversion as a function of time for three butane pressures: 2, 4, and 10 bars. Clearly increasing the butane has a positive effect not only on the conversion but also on the deactivation. When looking at the intermediate pressure ( $P=4$ bars), the proposed model from the modelization of the data by two exponentials is clearly proved: there is a first rapid deactivation followed by a second step where the conversion decreases only slightly with time. At high pressure, the first deactivation is so rapid that it is not observed and only a slow deactivation is observed. At low pressure the situation is more complicated, with the two deactivation exponentials being not very different. In terms of selectivity the pressure has no effect on the curves selectivity $=f$ (conversion) as it could be expected.

\section{Conclusion}

We have shown that the silica-supported heteropolyacids are active, even without hydrogen, in $n$-butane isomerization. The impregnation solvent has a nonnegligible effect on the catalytic properties. Very low polyoxometalate loadings result in inactive systems in the case of phosphotungstic acid. The silica-supported silicotungstic acid is not only more active but also more selective than the phosphotungstic compound. In presence of platinum selectivity values higher than $97 \%$ for isobutane are achieved. At high temperature the catalysts become less active, probably due to a loss of protons by dehydration. Studies on supports which could have an effect on the activity and/or the selectivity (while silica can be considered as inert from this point of view) are in progress.

\section{Conflict of Interests}

The authors declare that there is no financial or competing conflict of interests for this work.

\section{References}

[1] J. N. Armor, "A history of industrial catalysis," Catalysis Today, vol. 163, no. 1, pp. 3-9, 2011.

[2] A. Galadima, J. A. Anderson, and R. P. K. Wells, "Solid acid catalysts in heterogeneous $n$-alkanes hydroisomerisation for increasing octane number of gasoline," Science World Journal, vol. 4, no. 3, pp. 15-22, 2009.

[3] M. Hino, S. Kobayashi, and K. Arata, "Reactions of butane and isobutane catalyzed by zirconium oxide treated with sulfate ion. Solid superacid catalyst," Journal of the American Chemical Society, vol. 101, no. 21, pp. 6439-6441, 1979.

[4] F. Garin, D. Andriamasinoro, A. Abdulsamad, and J. Sommer, "Conversion of butane over the solid superacid $\mathrm{ZrO}_{2} / \mathrm{SO}_{4}^{2-}$ in the presence of hydrogen," Journal of Catalysis, vol. 131, no. 1, pp. 199-203, 1991.

[5] F. R. Chen, G. Coudurier, J. F. Joly, and J. C. Vedrine, "Superacid and catalytic properties of sulfated zirconia," Journal of Catalysis, vol. 143, no. 2, pp. 616-626, 1993.

[6] M. Hino and K. Arata, "Reactions of butane and isobutane catalysed by titanium oxide treated with sulphate ion. Solid superacid catalyst," Journal of the Chemical Society, pp. 1148-1149, 1979.

[7] M. Hino and K. Arata, "Synthesis of solid superacid of tungsten oxide supported on zirconia and its catalytic action for reactions of butane and pentane," Journal of the Chemical Society, pp. 1259-1260, 1988.

[8] C. L. Hill, "Introduction: polyoxometalates multicomponent molecular vehicles to probe fundamental issues and practical problems," Chemical Reviews, vol. 98, pp. 1-2, 1998.

[9] I. V. Kozhevnikov, "Catalysis by heteropoly acids and multicomponent polyoxometalates in liquid-phase reactions," Chemical Reviews, vol. 98, pp. 171-198, 1998.

[10] N. Mizuno and M. Misono, "Heterogeneous catalysis," Chemical Reviews, vol. 98, no. 1, pp. 199-217, 1998.

[11] S. Suzuki, K. Kogai, and Y. Ono, "Isomerization of alkanes over a palladium salt of heteropolyacid," Chemistry Letters, vol. 13, no. 5, pp. 699-702, 1984. 
[12] K. Na, T. Okuhara, and M. Misono, "Skeletal isomerization of $n$-butane catalyzed by an acidic cesium salt of 12-tungstophosphoric acid," Chemistry Letters, vol. 22, no. 7, pp. 1141-1144, 1993.

[13] K. Na, T. Okuhara, and M. Misono, "Isomerization of $n$-butane over bifunctional platinum-heteropoly compounds in the presence of hydrogen," Journal of the Chemical Society, pp. 14221423, 1993.

[14] K. Na, T. Okuhara, and M. Misono, "Skeletal isomerization of $n$-butane over caesium hydrogen salts of 12-tungstophosphoric acid," Journal of the Chemical Society, vol. 91, pp. 367-373, 1995.

[15] T. Suzuki and T. Okuhara, "Mechanism of skeletal isomerization of $n$-butane using $1,4-{ }^{13} \mathrm{C}_{2}$ - $n$-butane on solid strong acids," Chemistry Letters, vol. 29, no. 5, pp. 470-471, 2000.

[16] Z. N. Ma, W. M. Hua, Y. Ren, H. Y. He, and Z. Gao, " $n$-butane isomerization over Cs-salts of $\mathrm{H}_{3} \mathrm{PW}_{12} \mathrm{O}_{40}$ : a mechanistic study by ${ }^{1}$ C MAS NMR," Applied Catalysis A, vol. 256, pp. 243-250, 2003.

[17] K. Na, T. Okuhara, and M. Misono, "Catalysis by heteropoly compounds: 34 . Skeletal isomerization of $n$-butane over Pt- or Pd-promoted cesium hydrogen salts of 12-tungstophosphoric acid," Journal of Catalysis, vol. 170, no. 1, pp. 96-107, 1997.

[18] K. Na, T. Iizaki, T. Okuhara, and M. Misono, "Molecular design of solid acid catalysts. Isomerization of $n$-butane catalyzed by acid cesium salts of 12-tungstophosphoric acid combined with platinum," Journal of Molecular Catalysis A, vol. 115, no. 3, pp. 449-455, 1997.

[19] K. Nowinska, R. Fiedorov, and J. Adamiec, "Catalytic activity of supported heteropoly acids for reactions requiring strong acid centres," Journal of the Chemical Society, vol. 87, pp. 749-753, 1991.

[20] Y. Liu, G. Koyano, and M. Misono, "Hydroisomerization of $n$-hexane and $n$-heptane over platinum-promoted $\mathrm{Cs}_{2.5} \mathrm{H}_{0.5} \mathrm{PW}_{12} \mathrm{O}_{40}$ (Cs2.5) studied in comparison with several other solid acids," Topics in Catalysis, vol. 11-12, no. 1-4, pp. 239-246, 2000.

[21] A. V. Ivanov, T. V. Vasina, V. D. Nissenbaum, L. M. Kustov, M. N. Timofeeva, and J. I. Houzvicka, "Isomerization of $n$-hexane on the Pt-promoted Keggin and Dawson tungstophosphoric heteropoly acids supported on zirconia," Applied Catalysis A, vol. 259, no. 1, pp. 65-72, 2004.

[22] R. Hubaut, B. Ouled Ben Tayeb, W. Kuang, A. Rives, and M. Fournier, "Mechanical mixtures of $\mathrm{Me}(\mathrm{Ni}, \mathrm{Pd}) \mathrm{Ce}$ oxides and silica-supported heteropolyacids: role and optimal concentration of each active species in $n$-hexane isomerization," Kinetics and Catalysis, vol. 47, no. 1, pp. 20-24, 2006.

[23] A. Gherib, A. Aouissi, A. Rives, M. Fournier, and R. Hubaut, "Isomerization of $n$-hexane over silica-supported heteropolyoxometallates promoted by Pt-Ce oxides," Chinese Journal of Catalysis, vol. 28, no. 12, pp. 1041-1046, 2007.

[24] A. Oulmekki and F. Lefebvre, " $n$-Hexane cracking over heteropoly acids, 1 . Treatment of data and temperature dependence of the catalyitc activity of $\mathrm{H}_{3} \mathrm{PW}_{12} \mathrm{O}_{40}$, Reaction Kinetics and Catalysis Letters, vol. 48, pp. 593-600, 1992.

[25] A. Oulmekki and F. Lefebvre, " $n$-hexane cracking over heteropoly acids, 2. Catalytic activity and thermal stability of $\mathrm{H}_{4} \mathrm{SiW}_{12} \mathrm{O}_{40}, \mathrm{H}_{6} \mathrm{P}_{2} \mathrm{~W}_{18} \mathrm{O}_{62}$ and $\mathrm{H}_{6} \mathrm{P}_{2} \mathrm{~W}_{21} \mathrm{O}_{71}\left(\mathrm{H}_{2} \mathrm{O}\right)_{3}$," Reaction Kinetics and Catalysis Letters, vol. 48, pp. 601-606, 1992.

[26] A. Oulmekki and F. Lefebvre, " $n$-Hexane cracking over heteropoly acids, 3. Silica supported heteropoly acids," Reaction Kinetics \& Catalysis Letters, vol. 48, no. 2, pp. 607-612, 1992.
[27] F. Lefebvre, " ${ }^{31} \mathrm{P}$ MAS NMR study of $\mathrm{H}_{3} \mathrm{PW}_{12} \mathrm{O}_{40}$ supported on silica: formation of $\left(\equiv \mathrm{SiOH}_{2}^{+}\right)\left(\mathrm{H}_{3} \mathrm{PW}_{12} \mathrm{O}_{40}^{-}\right)$," Journal of the Chemical Society, Chemical Communications, pp. 756-757, 1992.

[28] S. M. Kulikov, M. N. Timofeeva, I. V. Kozhevnikov, V. I. Zaikovskii, L. M. Plyasova, and I. A. Ovsyanikova, "Adsorption of the heteropolyacid $\mathrm{H}_{4} \mathrm{SiW}_{12} \mathrm{O}_{40}$ by porous substrates," Bulletin of the Academy of Sciences of the USSR Division of Chemical Science, vol. 38, no. 4, pp. 687-691, 1989.

[29] A. D. Newman, D. R. Brown, P. Siril, A. F. Lee, and K. Wilson, "Structural studies of high dispersion $\mathrm{H}_{3} \mathrm{PW}_{12} \mathrm{O}_{40} / \mathrm{SiO}_{2}$ solid acid catalysts," Physical Chemistry Chemical Physics, vol. 8, no. 24, pp. 2893-2902, 2006.

[30] A. Thomas, C. Dablemont, J. M. Basset, and F. Lefebvre, "Comparison of $\mathrm{H}_{3} \mathrm{PW}_{12} \mathrm{O}_{40}$ and $\mathrm{H}_{4} \mathrm{SiW}_{12} \mathrm{O}_{40}$ heteropolyacids supported on silica by ${ }^{1} \mathrm{H}$ MAS NMR," Comptes Rendus Chimie, vol. 8, no. 11-12, pp. 1969-1974, 2005.

[31] N. Legagneux, A. De Mallmann, E. Grinenval, J. M. Basset, and F. Lefebvre, "Grafting reaction of organotin complexes on silica catalyzed by tungstic heteropolyacids," Inorganic Chemistry, vol. 48, no. 18, pp. 8718-8722, 2009.

[32] N. Legagneux, E. Jeanneau, A. Thomas et al., "Grafting reaction of platinum organometallic complexes on silica-supported or unsupported heteropolyacids," Organometallics, vol. 30, no. 7, pp. 1783-1793, 2011.

[33] G. Caiero, R. H. Carvalho, X. Wang et al., "Activation of $\mathrm{C}_{2}-\mathrm{C}_{4}$ alkanes over acid and bifunctional zeolite catalysts," Journal of Molecular Catalysis A, vol. 255, pp. 131-158, 2006.

[34] M. Guisnet, P. Bichon, N. S. Gnep, and N. Essayem, “Transformation of propane, $n$-butane and $n$-hexane over $\mathrm{H}_{3} \mathrm{PW}_{12} \mathrm{O}_{40}$ and cesium salts. Comparison to sulfated zirconia and mordenite catalysts," Topics in Catalysis, vol. 11-12, no. 1-4, pp. 247-254, 2000.

[35] S. S. Chen, R. C. Wilhoit, and B. J. Zwolinski, “Thermodynamic properties of normal and deuterated methanols," Journal of Physical and Chemical Reference Data, vol. 6, no. 1, pp. 105-112, 1977.

[36] C. Travers, N. Essayem, M. Delage, and S. Quelen, "Heteropolyanions based catalysts for paraffins isomerization," Catalysis Today, vol. 65, no. 2-4, pp. 355-361, 2001. 

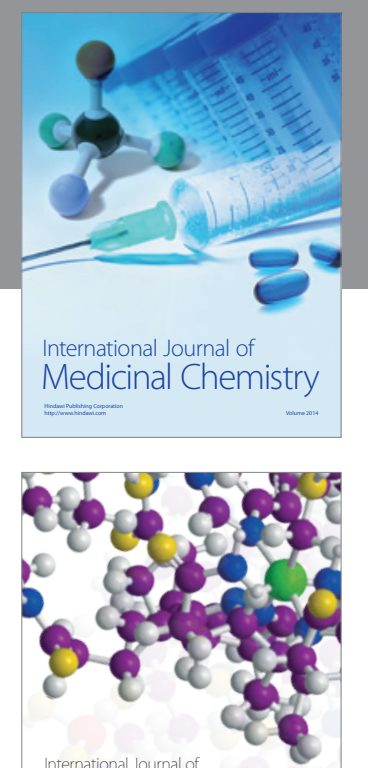

\section{Carbohydrate} Chemistry

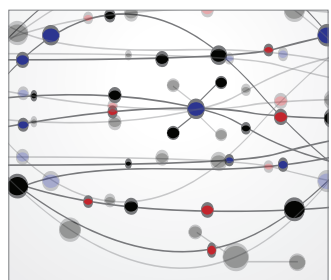

The Scientific World Journal
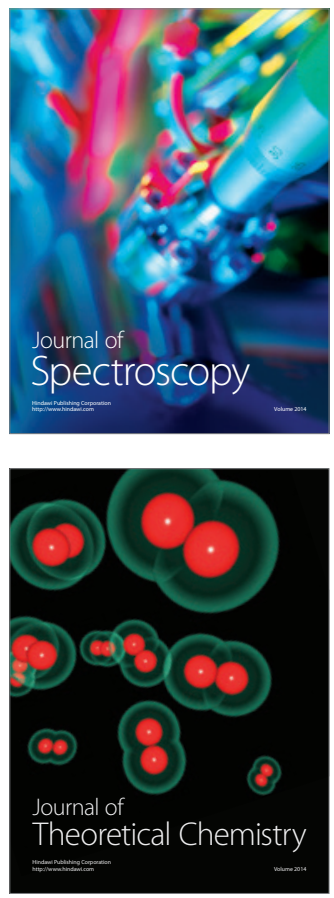
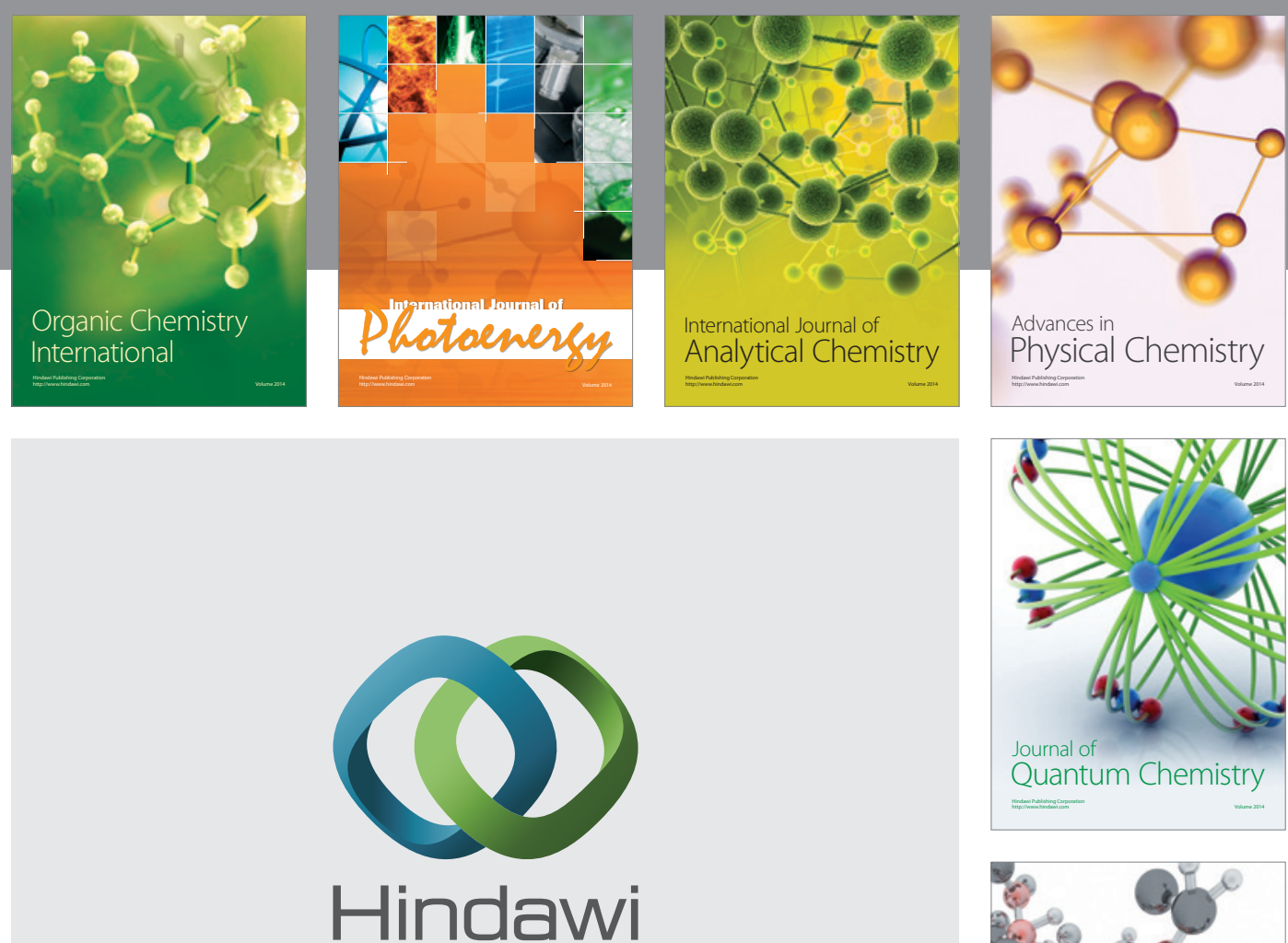

Submit your manuscripts at

http://www.hindawi.com

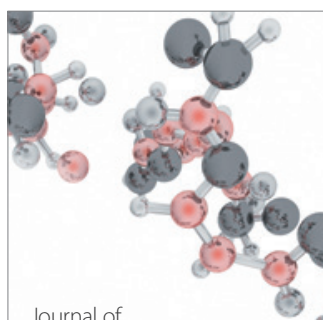

Analytical Methods

in Chemistry

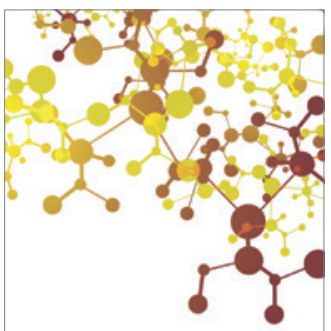

Journal of

Applied Chemistry

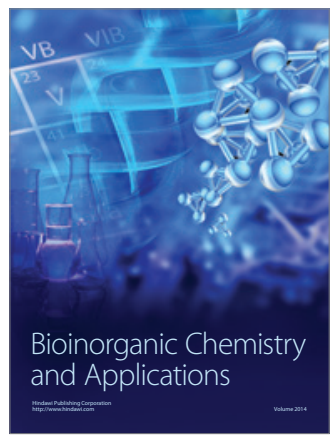

Inorganic Chemistry
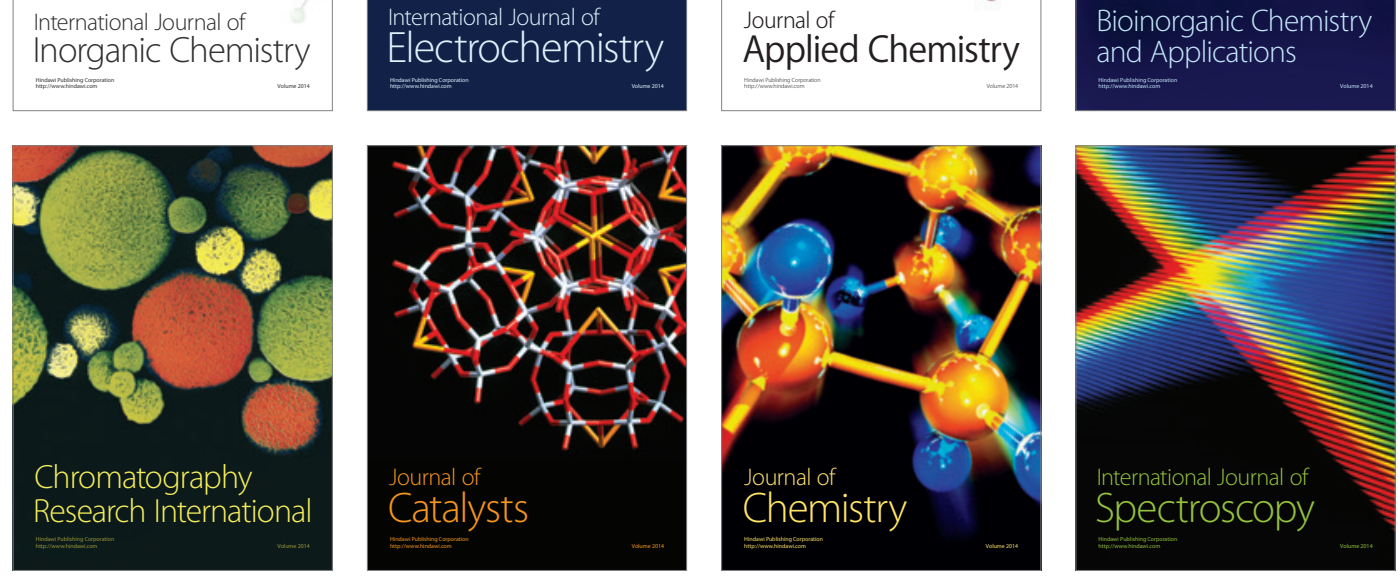